\title{
Management of Induced Menopause in Gynaecological Cancers and Their Challenges
}

\author{
Prashant Purohit ${ }^{1} \cdot$ Jennifer Sassarini ${ }^{2} \cdot$ Mary Ann Lumsden ${ }^{3}$ \\ Published online: 25 May 2019 \\ (C) The Author(s) 2019
}

\begin{abstract}
Purpose of Review The consequence of treatment for gynaecological cancers can cause sudden onset of intense menopausal symptoms, such as vasomotor symptoms, sexual dysfunction and emotional instability. Hormone replacement therapy (HRT) is often effective and can overcome these unpleasant and severe symptoms. However, data regarding its safety remains controversial. The big question therefore is whether HRT in gynaecological cancer survivors is possible. This is due to the fear of disease relapse. So, the purpose of this study was to review the evidence regarding cancer recurrence or death following use of HRT in survivors of gynaecological cancers.

Recent Findings For endometroid endometrial cancer, most of the retrospective studies concluded that there was no increase in recurrence rate of endometrial cancers in HRT versus non-HRT users. HRT should be particularly avoided in epithelial ovarian tumours particularly serous cancers and serous borderline tumours due to expression of oestrogen receptors. Given the lack of evidence on the impact of HRT on recurrence and disease-free survival in survivors of cervical cancers, it would seem perfectly reasonable to prescribe HRT, particularly if they are premenopausal. Many clinical guidelines would consider the use of HRT to be contraindicated in breast cancer survivors based on limited RCT evidence. Summary Current scientific data, comprising mainly of retrospective studies, suggest that recurrence rates and survival are comparable between HRT users and non-users. Women should know the paucity of safety data regarding the use of HRT. Wherever possible, non-hormonal alternatives to HRT should be considered in all women. If non-hormonal alternatives fail to achieve adequate control of symptoms, then it is possible to consider the HRT after careful counselling of the patient as well as involvement of the oncology team in the decision-making process. However, more robust randomised controlled trials are needed to get convincing data regarding the safety of HRT in gynaecological cancer survivors.
\end{abstract}

Keywords Hormone replacement therapy (HRT) - Gynaecological cancers · HRT alternatives · Menopause · Vulvovaginal atrophy $($ VVA) $\cdot$ Cancer survivors

This article is part of the Topical Collection on Advances in Gynaecologic Oncology Screening Technologies

Prashant Purohit prashant.purohit@nhs.net

$1 \quad$ ST7 Speciality Trainee in Obstetrics and Gynaecology, Glasgow Royal Infirmary, Glasgow, UK

2 Consultant Obstetrician and Gynaecologist, Princess Royal Maternity, Glasgow Royal Infirmary, Glasgow, UK

3 Professor of Gynaecology, University of Glasgow, Glasgow, UK

\section{Introduction}

One of the consequences of treating gynaecological and breast cancer in younger women is abrupt loss of ovarian function. As a result of iatrogenic menopause, these women often have to deal with intense and sudden onset of menopausal symptoms such as vasomotor symptoms, genito-urinary dysfunction, sleep and mood disturbances. These symptoms are often exacerbated by the cancer treatment [1]. Expansion of screening programmes, increasing patient awareness, early diagnosis, and progress in the treatment of gynaecological cancer has led to prolonged survival of women living with gynaecological cancers. As a result, there is a demand for greater attention towards 
improving quality of life and minimising long-term consequences of oestrogen deficiency in these women. It is often difficult to provide appropriate advice regarding hormonal replacement therapy (HRT) in women after gynaecological cancer treatment due to paucity of evidence and published guidance. In addition, the safety of HRT in this group of women is controversial due to the possible hormonedependent nature of some of the cancers and hence opinion is divided.

Conventional HRT is highly effective in alleviating menopausal symptoms, improving quality of life and in reducing the long-term risk of osteoporosis and cardiovascular disease $[2,3]$. The major concern about HRT use in gynaecological and breast cancer survivors is the fear of recurrence. This article reviews the available evidence specific to the risk of HRT in women who are survivors of gynaecological and breast cancer and also provides evidence-based recommendations regarding the use of HRT and its alternatives. This review is based on the available literature which consists mainly of retrospective, observational and case-control studies.

\section{HRT and Endometrial Cancer (EC)}

Uterine cancer is the most common gynaecological cancer in the UK second only to breast cancer with 8984 cases diagnosed in 2015 [4]. The incidence of this is increasing secondary to the obesity epidemic. Although most commonly seen in postmenopausal women, $30 \%$ of cases are seen in premenopausal women $[5,6]$. The standard treatment is hysterectomy and bilateral salpingo-oopherectomy (with or without chemoradiotherapy), and as such these women may suffer from sudden iatrogenic morbidity associated with menopause.

The commonest histological subtype is endometrioid endometrial cancer and its association with unopposed oestrogen exposure is well established [6, 7]. Several studies have reported higher risks of endometrial cancer in HRT users than in non-users, but this was confined to particular sequential regimens; conjugated equine oestrogen and medroxy progesterone acetate, which is rarely used in the UK. Moreover, the incidence has been shown to be decreased in users of continuous combined HRT [8, 9]. As a result, advice on HRT use, particularly in early-stage endometrial cancer is uncertain.

Most of the studies published in the literature are in younger women, particularly with a history of type 1 endometrial carcinoma and early stages of the disease. There have been a few retrospective studies which concluded that there was no increase in recurrence rate of endometrial cancers in HRT versus non-HRT users [10-13, and). In a prospective trial with 49.1 months follow-up, Ayhan et al. 2006 found no increase in recurrence rate of endometrial cancer after the use of HRT [14]. However, the number of subjects in this study was low (50 HRT users vs 61 NON users). The only prospective randomised controlled trial ( $\mathrm{RCT}$ ) was from the Gynecologic Oncology Group (GOG) [15]. It randomised 1236 women with stages 1-2 adenocarcinoma to oestrogens alone or to placebo group for 3 years. As a result of the publication of the WHI study [16], this study was closed prematurely after a mean follow-up of 35 months. No significant difference was observed in the recurrence rate, which was extremely low in both groups $(2.1 \%$ in the 618 HRT users versus $1.9 \%$ in the placebo groups).

No other study has so far reported a detrimental effect of HRT in early-stage endometrial cancer survivors. However, these studies vary in study design, timing of HRT after surgery, uniformity with regard to doses, duration of administration and addition of progestin. Only one study was randomised, therefore patients who wish to start HRT may be those who will benefit less from treatment. Although the results do not completely exclude the possibility of HRT increasing the risk of recurrence, they suggest that the magnitude of such a risk is not large.

Serous papillary and clear cell carcinomas are both aggressive variants of EC with a poor prognosis, even when diagnosed at an early stage. They account for approximately $8 \%$ of all EC and occur mainly in postmenopausal women. They lack oestrogen and progesterone receptors and thus are not considered to be stimulated when HRT is used after surgical treatment. Uterine sarcomas are a heterogeneous group of EC including carcinosarcomas, leiomyosarcomas, adenosarcomas and endometrial stromal sarcomas. Only the latter type is considered oestrogen-dependent as it expresses oestrogen and progesterone receptors and HRT should be avoided in them [17]. However, there are no studies published regarding the safety of HRT in these histological subtypes and the impact of HRT is unknown. Also, most occur in postmenopausal women.

\section{HRT and Ovarian Cancers}

Ovarian cancer is the next most common gynaecological cancer after uterine cancer with 7270 cases diagnosed in 2015 [4]. Over $90 \%$ of ovarian cancers are of epithelial origin and it is the leading cause of death amongst gynaecological malignancies in many areas of the world $[18,19]$. At diagnosis, more than $75 \%$ of women have advanced stage disease and their 5 year survival is poor, not exceeding $45 \%$. For this reason, focus upon quality of life after treatment may become increasingly important for some women and relief of menopausal symptoms may, for some, outweigh the fear of recurrence [18].

In preclinical studies, the pathogenesis seems to be at least partly hormonally influenced [20] and a number of in vitro experiments have indicated that oestrogen is capable of promoting the growth of ovarian cancer cells [21]. Also, a meta- 
analysis of 21,488 post-menopausal women who used HRT for over 5 years showed an increased risk of ovarian cancer (Collaborative Group On Epidemiological Studies Of Ovarian Cancer, 2015) although numerically, the absolute increase in risk was small (1/1000 users) [22]. Antiestrogens and aromatase inhibitors such as tamoxifen and letrozole have now been used in relapsed cases of ovarian cancers and who do not tolerate first-line chemotherapy. This is with the understanding that certain epithelial ovarian tumours express oestrogen and progesterone receptors [23-25, and).

However, there are no clear data demonstrating adverse outcomes in ovarian cancer patients taking HRT. A few observational studies and RCT have demonstrated favourable outcome in ovarian cancer survivors using HRT for over 24 months versus non-users [20, 26-30). For women with borderline tumours, observational studies using HRT has shown a better 5 -year survival rate as compared to invasive tumours [27].

Low-grade serous carcinomas are almost always diffusely positive with oestrogen receptor and HRT is normally avoided in this subtype of ovarian cancer [23]. 10\% of epithelial ovarian cancers are borderline tumours [31]. These are heterogeneous tumours and treatment is always individualised. Expert opinion is that these are tumours with potential to turn into low-grade serous cancers and hence better to avoid HRT in serous borderline tumours depending on the severity of the symptoms. There are no studies for use of HRT after clear cell and endometrioid ovarian cancers. However, due to the hormone-dependent nature of some of these tumours, some believe that there is a theoretical risk of disease reactivation with the use of unopposed or cyclical HRT.

Ovarian germ cell and sex cord stromal tumours are often seen in young premenopausal women and thought to be hormone-dependent. No studies examining the use of HRT in these subsets are available. Whilst it can be considered in early stage and unilateral tumours, HRT should be avoided and alternatives discussed [18].

\section{HRT and Cervical Cancer}

Pre-invasive and early invasive cervical cancers are often treated with conservative surgery in young women, therefore, HRT is usually considered in advanced stages. HRT has never been linked to development of squamous cell carcinoma of the cervix which amounts to $80 \%$ of the cases. There is, however, epidemiological data linking the oral contraceptive pill to adenocarcinoma of the cervix with a relative risk of 2.2 after 10year use [32]. There is no data on HRT use in these women. Ploch et al. reported no impact on 5-year survival with HRT use in stage $1 \& 2$ cervical cancers and noted fewer radiotherapy complication rates in these women [33]. Given the lack of evidence on the impact of HRT on recurrence and disease-free survival, it would seem perfectly reasonable to prescribe HRT for survivors of cervical cancers, particularly as they are likely to be premenopausal.

\section{HRT and Vulvo-Vaginal Cancers}

These cancers account for a very small number of cases, mainly affecting postmenopausal women. Apart from some controversy about melanoma due to unconfirmed reports that it is hormone-dependent, cancers of the vulva and vagina are not hormone-dependent and it is believed that there is no contraindication to the use of HRT in women treated for vulva or vaginal neoplasm [34].

\section{HRT and Breast Cancers}

In 2015, there were 55,122 new cases of invasive breast cancer diagnosed across the UK which accounts for almost one third of all diagnosed cancers in women [4]. In UK, over the last decade, breast cancer mortality rates have decreased by more than a fifth (22\%) secondary to early diagnosis and advancements in treatment. As a consequence of primary chemo-radiation and adjunctive endocrine therapy, many breast cancer survivors suffer from severe and sudden onset of climacteric symptoms and reduced quality of life. Oestrogen receptor (ER) and progesterone receptor (PR) positivity is found in $75 \%$ of breast cancers [35]. In these women, the most effective treatment for menopausal symptoms would be HRT, however, its use in breast cancer survivors is varied and controversial based on the fact that prevention of recurrence of hormone receptor-positive tumours involves using adjuvant anti-oestrogen therapy such as tamoxifen and/or aromatase inhibitors that decrease the circulating level of oestradiol to almost zero [36, 37••].

$\mathrm{Col}$ et al. reported meta-analyses of eight studies in Stage 1-4 breast cancer survivors who used oestrogen only or oestrogen + progesterone HRT. These showed reduced breast cancer recurrence over a 5-year follow-up period in women using HRT [38]. However, this was found to be confounded by selection bias. Several other observational studies suggested that HRT after breast cancer has no adverse impact on recurrence and mortality [39-42].

Many clinical guidelines would consider the use of HRT to be contraindicated in breast cancer survivors based on limited

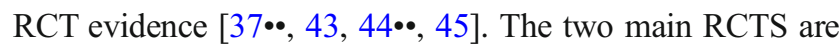
the HABITS (hormonal replacement therapy after breast cancer - is it safe?) and Stockholm trial [46-48]. Both trials compared oestrogen with or without a progestogen against a placebo. Although there was no difference in recurrence rates in HRT users, the Stockholm trial (Hazard Ratio -HR 0.82) was prematurely stopped due to high recurrences in the 
HABITS trial (HR2.2). The adverse outcome in HABITS has been imputed to higher progestogen exposure and less concomitant tamoxifen use compared with the Stockholm trial. Another RCT using tibolone also found an increased risk of recurrence in breast cancer survivors (HR 1.40) [49]. Due to the above data, HRT is usually contraindicated after breast cancer diagnosis. However, if alternatives to HRT fail to achieve adequate control of symptoms, then it is possible to consider the HRT after careful counselling of the patient as well as involvement of the oncologist and breast team in the decision-making process.

\section{HRT in BRCA 1 \& BRCA 2 Gene Carriers}

The National Comprehensive Cancer Network (NCCN) recommends risk reducing bilateral salpingo-oophorectomy (RRBSO) for women with BRCA1 mutations between ages 35 and 40 and for BRCA2 mutations between 40 and 45 years in order to prevent ovarian and fallopian tube cancers [50]. Thus, RRBSO significantly decreases overall mortality and risk of tubo-ovarian cancers in BRCA positive women with or without history of breast cancer as well as lowers the risk of first diagnosis of breast cancer in BRCA mutation carriers [51-54].The consequence of RRBSO is iatrogenic early menopause. If these women do use HRT, it results in overall decreased mortality $[55,56]$. However, the controversy here is the potential augmentation of already elevated breast cancer risk with the use of HRT in BRCA gene carriers.

The Women's Health Initiative (WHI) trial was stopped prematurely after demonstrating an increased risk of breast cancer in the oestrogen plus progesterone arm (HR 1.26) as compared to placebo after 5.2 years follow-up. Given that WHI participants had an average age of 63 years at enrolment, it is unclear how these data apply to women with premature surgical menopause. The other interesting fact from the WHI trial was that this increased risk in breast cancer was seen with the use of oestrogen plus progesterone HRT (E+P) (HR 1.26), but not with oestrogen-only HRT (HR 0.77) [3].

Since then, both prospective and retrospective studies have been published, demonstrating that the use of HRT is not associated with increased risk of breast cancer after RRBSO in BRCA carriers [57-59, 60••]. In the prospective, cohort study of premenopausal BRCA carriers (PROSE), RRBSO was significantly associated with reduction of breast cancer risk $(\mathrm{HR}=0.40)$ without alteration of this risk with the use of HRT of any type (HR0.37). In this study, women predominantly took oestrogen alone HRT rather than oestrogen plus progesterone [57]. In 2016, Kotsopoulos et al. reported no adverse effect of oestrogen-alone or of combined oestrogen plus progesterone $(\mathrm{E}+\mathrm{P})$ formulations on breast cancer risk in BRCA1 mutation carriers after RRBSO [59]. A subset analysis of this study showed oestrogen-containing HRT was associated with an $18 \%$ reduction in breast cancer risk (HR $0.82,95 \%$ CI $0.69-0.97, p=0.02$ ) while each year of progestin-containing HRT (progestin-alone or E $+\mathrm{P}$ ) was associated with a non-significant $(14 \%)$ increase in breast cancer risk (HR 1.14, 95\% CI 0.90-1.46, $p=0.28$ ) [60••].

Finally, there has been some consideration of interval salpingectomy with delayed oophorectomy (ISDO) for risk reduction which can reduce the adverse effects of early menopause by delaying its onset. Currently, there is insufficient data to recommend it over RRBSO in BRCA 1 \& BRCA2 carriers. The fear of breast cancer risk by patients and providers is often the major deterrent from starting HRT. However, based on the available literature, breast cancer risk reduction following RRBSO in premenopausal BRCA carriers without a history of breast cancer is not changed due to HRT. Hence, with the current available data, it would be safe and beneficial to use HRT in these women.

\section{Management Strategies}

The key principles for management are to determine the age of the women, type and prognosis of the cancer, severity of the signs and symptoms related to oestrogen deficiency and the extent to which this impacts the quality of life. This allows treatment to be individually tailored based on these assessments. For mild symptoms, maintenance of health, lifestyle modifications or over the counter options may be sufficient. Moderate or severe signs or symptoms usually require pharmacological management. Routine testing for hormone status in tumours should now be considered and this will help to determine the hormone-dependent nature of the gynaecological tumour and guide discussions regarding the use/consideration of HRT.

The absolute risks of each potential complication of HRT must be interpreted once an individual's background risk has been considered. Although HRT may increase the relative risk of a complication occurring, the overall absolute risk may remain low and this risk must be carefully presented to the individual. Multidisciplinary planning can often help with decision making regarding best management option for menopausal symptoms. Discussing systemic HRT in breast cancer sufferers is outside the scope of this review since it is an absolute contraindication. Below are some of the alternatives to systemic HRT that can be considered in women in whom HRT is contraindicated or for those who wish to avoid it.

\section{Lifestyle Modifications}

There is some evidence that healthy lifestyle behaviours can improve some symptoms of the menopause - particularly vasomotor symptoms, such as hot flashes and night sweats. There is also some evidence that women who are more active 
tend to have fewer symptoms of the menopause [61]. Furthermore, a calorie-controlled diet, with an aim to lose $10 \%$ or more of the body weight, may modify the incidence of VMS [62]. Diet rich in calcium (1000 mg/day) and Vitamin $\mathrm{D}(10 \mathrm{mcg} /$ day $)$ will help prevent development of osteoporosis and hence risk of fractures. Stopping smoking and cutting down on alcohol may also reduce the frequency of hot flashes as well as the risk of heart disease and osteoporosis long term [63].

\section{Alternatives to HRT}

Most alternative therapies are evaluated in respect to vasomotor symptoms, and some may also have an effect on mood (Table 1). The placebo effect has been reported to be as great as 30-50\% in many studies in addition to its baseline effect and for some, that in itself might be considered a treatment option [64].

Alternative Techniques Acupuncture, yoga, reflexology, homoeopathy and hypnosis have been described to be useful in managing menopausal symptoms but no strong data exists to support this $[65,66]$. As with the therapies mentioned above, whilst many women may find some of these techniques helpful, more research is required to fully understand their mechanism of action and effectiveness. However, when used properly with advice from qualified professionals, it is unlikely that any harm will be caused. NICE (2015) recommends Cognitive Behavioural Therapy (CBT) as a treatment option for anxiety experienced by women during the menopause transition and post-menopause [67]. CBT, developed specifically for menopausal symptoms, can help women with vasomotor symptoms and has been found to be effective in three clinical trials for women going through the menopause and for breast cancer patients [68-70].

\section{Management of Vulvo-Vaginal Atrophy (VVA)}

The genito-urinary tract is where the most significant localised menopausal side effects are seen. Loss of oestrogen results in a decrease in the number of parabasal cells, an increase in vaginal $\mathrm{pH}$, as well as increased dryness and susceptibility to infections. Oestrogen deficiency also results in atrophy of the bladder and urethral epithelium making it susceptible to infections and symptoms of urinary frequency and urgency, nocturia, dysuria and incontinence are noted [71, 72]. Systemic hormone replacement therapy (HRT) can alleviate vaginal symptoms. The rise in serum oestradiol levels stimulates revascularisation and regeneration of the collagen of vaginal and lower urinary tract epithelium. However, the British Menopause Society and National Institute of Health and

Table 1 Alternatives to HRT

\begin{tabular}{|c|c|c|c|}
\hline Class and drug & Adverse effect & Dose & Precaution \\
\hline \multicolumn{4}{|l|}{ a) Prescribable } \\
\hline SNRI-Antidepressant & Dizziness, sexual dysfunction & $\begin{array}{l}\text { Venlafaxine } 37.5 \mathrm{mg} \text { daily to } \\
\text { max } 150 \mathrm{mg} / \text { day }\end{array}$ & $\begin{array}{l}\text { No interaction with } \\
\text { cytochrome } \mathrm{P} 450 \text { so it may } \\
\text { be the safest choice for } \\
\text { patients on anticancer drugs }\end{array}$ \\
\hline SSRI-antidepressants & $\begin{array}{l}\text { Nausea, dizziness, sexual } \\
\text { dysfunction, short term } \\
\text { aggravation of } \\
\text { anxiety/depression }\end{array}$ & $\begin{array}{l}\text { Paroxitine } 10-20 \mathrm{mg} \\
\text { Citalopram } 20 \mathrm{mg} \\
\text { Sertraline } 25-50 \mathrm{mg} \\
\text { Fluoxitine } 20 \mathrm{mg}\end{array}$ & $\begin{array}{l}\text { Drug interaction: Interacts } \\
\text { with enzyme cytochrome } \\
\text { P450 (CYN10) }\end{array}$ \\
\hline Central anti-hypertensive & $\begin{array}{l}\text { Sleep disturbance, dry mouth, } \\
\text { nausea and fatigue }\end{array}$ & $\begin{array}{l}\text { Clonidine } 25-150 \mathrm{mcg} / \mathrm{day} \\
\text { (licenced option) }\end{array}$ & $\begin{array}{l}\text { Slow titration of doses needed. } \\
\text { Interaction with other } \\
\text { anti-hypertensives }\end{array}$ \\
\hline Antiepileptic/analgesic & $\begin{array}{l}\text { Dry mouth dizziness, } \\
\text { drowsiness and weight gain } \\
\text { (Gabapentin » Pregabalin) }\end{array}$ & $\begin{array}{l}\text { Gabapentin } \\
\quad 300-900 \mathrm{mg} / \text { daily } \\
\text { Pregabalin } 50-300 \mathrm{mg} / \text { day }\end{array}$ & Weight gain \\
\hline \multicolumn{4}{|l|}{ b) Over the counter medications } \\
\hline Phytoestrogens & & $\begin{array}{l}\text { No more than Normal levels } \\
\text { of dietary Intake }\end{array}$ & $\begin{array}{l}\text { Poor quality evidence and } \\
\text { inconsistent data }\end{array}$ \\
\hline $\begin{array}{l}\text { Herbal remedies-Black } \\
\text { Cohosh }^{\mathrm{a}} \text {, St Johns wart, } \\
\text { Evening Primrose }\end{array}$ & $\begin{array}{l}\text { Constipation, arrhythmia, } \\
\text { weight gain, abdominal } \\
\text { cramps }\end{array}$ & $\begin{array}{l}\text { No recommendation on } \\
\text { dosing }\end{array}$ & $\begin{array}{l}\text { Many contain steroid } \\
\text { hormones (including } \\
\text { oestrogen). Not tested for } \\
\text { safety and efficacy. Drug } \\
\text { interactions }\end{array}$ \\
\hline
\end{tabular}

\footnotetext{
${ }^{a}$ Black cohosh is contraindicated in patients who have active liver disease or a history of liver damage. Liver toxicity has been associated with contaminants in black cohosh. But there is no causality data to back up this suggestion. It is available over the counter in Europe
} 
Clinical Excellence (NICE) recommend that when the symptoms are predominantly vaginal or urogenital, topical treatment should be used [71].

The following table summarises different options for VVA. Usually, non-hormonal options are the first line of treatment in women with breast and hormone-dependent gynaecological cancers (Tables 1 and 2). There have been no concerns with the safety and their use in these women. High-sensitivity assays have demonstrated that all vaginal oestrogen preparations result in a minor degree of systemic absorption but not exceeding normal postmenopausal levels [45]. Data regarding the safety of vaginal oestrogen therapy in breast cancer survivors are limited. Low-dose vaginal oestrogen in women taking the anti-oestrogens like tamoxifen might be theoretically safer than in women not receiving these agents because of blockade of some possible effects of systemic oestrogen absorption [73]. Some observational and case-controlled data show reassuring results with the use of vaginal oestrogen concurrently with tamoxifen $[41,73,74]$. However, the same is not available for aromatase inhibitors. Therefore, in general, the use of vaginal oestrogen is discouraged in women using aromatase inhibitors in breast cancer survivors [37••, 44••]. Detailed counselling of the patient, as well as liaison with the oncology team, is essential before considering local hormonal therapy in these women and, if used, should be at the lowest dose possible.
In 2014, a meta-analysis concluded that there is no increased risk of recurrence in women who are taking systemic HRT following treatment of endometrial cancer [75]. Although there have been some concerns regarding the use of systemic treatment following ovarian cancer, there are no data to suggest an increased risk of recurrence with either systemic or local oestrogen therapy [17].

Ospemiphene, an oral SERM, has been approved in Europe and North America for the treatment of dyspareunia secondary to VVA in healthy postmenopausal women. However, current FDA labelling in the USA recommends against the use of ospemiphene in women with a history of breast cancer, until results from an adequately powered RCT of its effect on the breast are available. Similar safety concerns exist with the use of tissue-selective oestrogen complex, phytoestrogens and testosterone/DHEA vaginal gels due to their potential estrogenic activity in women with breast and other gynaecological cancers.

\section{What's on the Horizon?}

Recent data suggest that neurokinin B in the arcuate nucleus mediates menopausal hot flashes. On this basis, two randomised placebo-controlled trials have evaluated the effects of oral neurokinin B receptor antagonists on hot flashes. Both agents (MLE 4901 and fezolinetant) reduced hot flash
Table 2 Management option for VVA

\begin{tabular}{|c|c|c|}
\hline Class and drug & Route/dose & Precaution \\
\hline \multicolumn{3}{|l|}{ A) Non-hormonal } \\
\hline $\begin{array}{l}\text { Vaginal moisturisers } \\
\text { and lubricants-SYLK, } \\
\text { Replens MD, Yes, } \\
\text { Vagisil }\end{array}$ & $\begin{array}{l}\text { Vaginal lubricants } \\
\text { just before sexual } \\
\text { intercourse. } \\
\text { Moisturisers twice } \\
\text { weekly }\end{array}$ & $\begin{array}{l}\text { Cost } \\
\text { Short-term relief } \\
\text { Useful in mild-moderate VVA }\end{array}$ \\
\hline Laser (Erbium and $\mathrm{CO}_{2}$ ) & Vaginal & Cost, limited data on safety and efficacy \\
\hline \multicolumn{3}{|l|}{ B) Hormonal } \\
\hline $\begin{array}{l}\text { Vaginal oestrogen: } \\
\text { Vagifem, Ovestin, } \\
\text { Orthogynest, Gynest, } \\
\text { Estring } \\
\text { Selective ER modulator }\end{array}$ & $\begin{array}{l}\text { Vaginal } \\
\text { Daily } \times 2 \text { weeks. } \\
\text { Twice weekly } \\
\text { Ospemiphene } \\
\quad 60 \mathrm{mg} \text { /daily }\end{array}$ & \\
\hline $\begin{array}{l}\text { Tissue-selective } \\
\text { oestrogen complex } \\
\text { treatment }\end{array}$ & $\begin{array}{l}\text { Oral (conjugated } \\
\text { oestrogen } \\
0.45 \mathrm{mg}+ \\
\text { Benzadoxifene } 20 \mathrm{mg} \text { ) }\end{array}$ & $\begin{array}{l}\text { Lack of safety data, caution in } \\
\text { women who have contraindications } \\
\text { to oestrogen }\end{array}$ \\
\hline $\begin{array}{l}\text { Phytoestrogen: } \\
\text { isoflavone } \\
\text { gel }\end{array}$ & Vaginal Gel & \\
\hline $\begin{array}{l}\text { Androgens and } \\
\text { DHEA }\end{array}$ & $\begin{array}{l}\text { Vaginal DHEA } \\
6.5 \mathrm{mg} / \text { night } \\
\text { Testosterone gel }\end{array}$ & \\
\hline
\end{tabular}


frequency and severity by $40 \%$ to $50 \%$ over placebo in postmenopausal women, with negligible side effects [76, 77]. As these inhibitors act on specific hot-flash mediating pathways, they show promise as effective, non-hormonal agents to treat hot flashes particularly useful in survivors of hormonedependent gynaecological cancers. Long-term safety data for these drugs are still awaited. This drug is currently used only in trial setting testing for effectiveness and appropriate dosing schedule.

\section{Conclusion}

Treatment for gynaecological cancer in young women can cause sudden onset of intense menopausal symptoms, mainly vasomotor symptoms and sexual dysfunction. Hormone replacement therapy (HRT) has often proved to be very effective in the treatment of these unpleasant and often severe menopausal symptoms. However, its safety remains controversial. We have reviewed English language literature and examined whether administration of HRT in this specific population is associated with more recurrences and worse prognosis. Current scientific data, comprising mainly of retrospective studies, suggest that recurrence rates and survival are comparable between HRT users and non-users. However, large randomised trials are missing and definitive conclusions cannot be drawn. Gynaecological cancer survivors using HRT should be informed about the lack of strong evidence regarding the risk of recurrence with the use of HRT. Positive effect of HRT on quality of life in these women cannot be disregarded. In this regard, additional welldesigned RCTs considering all potential confounding factors, including cancer characteristics and treatment, different types of HRT, the disease-free-interval before HRT initiation and the duration of HRT use are needed to obtain conclusive recommendations.

In the meantime, what should we do? It is important that the available literature is interpreted with caution and presented to each woman enabling every patient to make informed decision with the support of the multidisciplinary specialist team regarding the use of HRT. If HRT is not desired or considered contraindicated, nonhormonal alternatives can be offered safely in the vast majority.

\section{Compliance with Ethical Standards}

Conflict of Interest Prashant Purohit, Jennifer Sassarini, and Mary Ann Lumsden declare no conflict of interest.

Human and Animal Rights and Informed Consent This article does not contain any studies with human or animal subjects performed by any of the authors.
Open Access This article is distributed under the terms of the Creative Commons Attribution 4.0 International License (http:// creativecommons.org/licenses/by/4.0/), which permits unrestricted use, distribution, and reproduction in any medium, provided you give appropriate credit to the original author(s) and the source, provide a link to the Creative Commons license, and indicate if changes were made.

\section{References}

Papers of particular interest, published recently, have been highlighted as:

•• Of major importance

1. Singh P, Oehler MK. Hormone replacement after gynaecological cancer. Maturitas. 2010;65:190-7.

2. MacLennan AH, Lester S, Moore V. Oral oestrogen replacement therapy versus placebo for hot flashes: a systematic review. Climacteric. 2001;4:58-74.

3. Rossouw JE, Anderson GL, Prentice RL, LaCroix A, Kooperberg $\mathrm{C}$, Stefanick ML, et al. Risks and benefits of oestrogen plus progestin in healthy postmenopausal women: principal results from the women's health initiative randomized controlled trial. JAMA. 2002;288:321-33.

4. Office for National Statistics, Cancer Registration statistics, UK, July 2017: https://www.ons.gov.uk/peoplepopulationandcommunity/ healthandsocialcare/conditionsanddiseases/bulletins/ cancerregistrationstatisticsengland.

5. Whitaker GK, Lee RB, Benson WL. Carcinoma of the endometrium in young women. Mil Med. 1986;151:25-31.

6. Grady D, Gebretsadik T, Kerlikowske K, Ernster V, Petitti D. Hormone replacement therapy and endometrial cancer risk: a meta-analysis. Obstet Gynecol. 1995;85:304-13 ISSN 0029-7844.

7. Furness S, Roberts H, Marjoribanks J, Lethaby A, Hickey M, Farquhar C. Hormone therapy in postmenopausal women and risk of endometrial hyperplasia. Cochrane Database Syst Rev. 2012;8: CD000402.

8. Weiderpass E, Adami HO, Baron JA, Magnusson C, Bergstr ö m R, Lindgren A, et al. Risk of endometrial cancer following estrogen replacement therapy with and without progestins. Journal of National Cancer Institute. 1999;91:1131-7.

9. Hill DA, Weiss NS, Beresford SA, Voigt LF, Daling JR, Stanford JL, et al. Continuous combined hormone replacement therapy and risk of endometrial cancer. Am J Obstet Gynecol. 2000;183:145661.

10. Suriano KA, McHale M, McLaren CE, Li KT, Re A, DiSaia PJ. Estrogen replacement therapy in endometrial cancer patients: a matched control study. Obstet Gynecol. 2001;97:555-60.

11. Lee RB, Burke TW, Park RC. Estrogen replacement therapy following treatment for stage I endometrial carcinoma. Gynecol Oncol. 1990;36:189-91.

12. Creasman WT, Henderson D, Hinshaw W, Clarke-Pearson DL. Estrogen replacement therapy in the patient treated for endometrial cancer. Obstet Gynecol. 1986;67:326-30.

13. Chapman JA, DiSaia PJ, Osann K, Roth PD, Gillotte DL, Berman ML. Estrogen replacement in surgical stage I and II endometrial cancer survivors. Am J Obstet Gynecol. 1996;175:1195-200.

14. Ayhan A, Taskiran C, Simsek S, Sever A. Does immediate hormone replacement therapy affect the oncologic outcome in endometrial cancer survivors? Int J Gynecol Cancer. 2006;16:805-8.

15. Barakat RR, Bundy BN, Spirtos NM, Bell J, Mannel RS, Gynecologic Oncology Group Study. Randomized double-blind 
trial of estrogen replacement therapy versus placebo in stage I or II endometrial cancer: a gynecologic oncology group study. J Clin Oncol. 2006;24(4):587-92.

16. Anderson GL, Judd HL, Kaunitz AM, Barad DH, Beresford SA, Pettinger M, et al. Effects of estrogen plus progestin on gynecologic cancers and associa diagnostic procedures: the women's health initiative randomized trial. JAMA. 2003;90(13):1739-48.

17. Guidozzi F. Estrogen therapy in gynecological cancer survivors. Climacteric. 2013;16:611-7.

18. Biliatis I, Thomakos N, Rodolakis A, Akrivos N, Zacharakis D, Antsaklis A. Safety of hormone replacement therapy in gynaecological cancer survivors. J Obstet Gynaecol. 2012;32: $321-5$.

19. Siegel RL, Miller KD, Jemal A. Cancer statistics, 2015. CA Cancer J Clin. 2015;65:5-29.

20. Eeles RA, Tan S, Wiltshaw E, Fryatt I, A'Hern RP, Shepherd JH, et al. Hormone replacement therapy and survival after surgery for ovarian cancer. BMJ. 1991;302:259-62.

21. Langdon SP, Hirst GL, Miller EP, Hawkins RA, Tesdale AL, Smyth $\mathrm{JF}$, et al. The regulation of growth and protein expression by estrogen in vitro: a study of 8 human ovarian carcinoma cell lines. $\mathrm{J}$ Steroid Biochem Mol Biol. 1994;50:131-5.

22. Collaborative Group On Epidemiological Studies Of Ovarian Cancer, Beral V, Gaitskell K, Hermon C, Moser K, Reeves G, et al. Menopausal hormone use and ovarian cancer risk: individual participant meta-analysis of 52 epidemiological studies. Lancet. 2015;385(May (9980)):1835-42.

23. McCluggage WG. Morphological subtypes of ovarian carcinoma: a review with emphasis on new developments and pathogenesis. Pathology. 2011;43:420-32.

24. Williams C, Simera I, Bryant A. Tamoxifen for relapse of ovarian cancer. Cochrane Database Syst Rev. 2010;(3):CD001034.

25. Sjoquist KM, Martyn J, Edmondson RJ, Friedlander ML. The role of hormonal therapy in gynecological cancers-current status and future directions. Int J Gynecol Cancer. 2011;21:1328-33.

26. Ursic-Vrscaj M, Bebar S, Zakelj MP. Hormone replacement therapy after invasive ovarian serous cystadenocarcinoma treatment: the effect on survival. Menopause. 2001;8:70-5.

27. Mascarenhas C, Lambe M, Bellocco R, Bergfeldt K, Riman T, Persson I, et al. Use of hormone replacement therapy before and after ovarian cancer diagnosis and ovarian cancer survival. Int $\mathrm{J}$ Cancer. 2006;119:2907-15.

28. Li L, Pan Z, Gao K, Zhang W, Luo Y, Yao Z, et al. Impact of postoperative hormone replacement therapy on life quality and prognosis in patients with ovarian malignancy. Oncol Lett. 2012;3:244-9.

29. Wen Y, Huang H, Huang H, Wu M, Shen K, Pan L. The safety of postoperative hormone replacement therapy in epithelial ovarian cancer patients in China. Climacteric. 2013;16:673-81.

30. Guidozzi F, Daponte A. Estrogen replacement therapy for ovarian carcinoma survivors: a randomized controlled trial. Cancer. 1999;86:1013-8.

31. Gotlieb WH, Chetrit A, Menczer J, Hirsh-Yechezkel G, Lubin F, Friedman E, et al. Demographic and genetic characteristics of patients with borderline ovarian tumors as compared to early stage invasive ovarian cancer. Gynecol Oncol. 2005;97:780-3.

32. Smith JS, Green J, Berrington de Gonzalez A, Appleby P, Peto J, Plummer M, et al. Cervical cancer and use of hormonal contraceptives: a systematic review. Lancet. 2003;361:1159-67.

33. Ploch E. Hormonal replacement therapy in patients after cervical cancer treatment. Gynecol Oncol. 1987;26:169-77.

34. Wren B. Hormonal therapy and genital tract cancer. Curr Opin Obstet Gynecol. 1996;8:38-41.

35. DeSantis CE, Fedewa SA, Goding Sauer A, Kramer JL, Smith RA, Jemal A. Breast cancer statistics, 2015: Convergence of incidence rates between black and white women. CA Cancer J Clin. 2016;66(January-February (1)):31-42.

36. Santen RJ, Allred DC, Ardoin SP, Archer DF, Boyd N, Braunstein GD, et al. Postmenopausal hormone therapy: an Endocrine Society scientific statement. J Clin Endocrinol Metab. 2010;95(7 Suppl 1): s1-s66.

37.• Stuenkel CA, Davis SR, Gompel A, Lumsden MA, Murad MH, Pinkerton JV, et al. Treatment of symptoms of the menopause: an Endocrine Society clinical practice guideline. J Clin Endocrinol Metab. 2015;100(11):3975-4011. A good evidence-based guideline in management of menopausal symptoms especially after gynaecological cancers.

38. Col NF, Kim JA, Chlebowski RT. Menopausal hormone therapy after breast cancer: a meta-analysis and critical appraisal of the evidence. Breast Cancer Res. 2005;7:R535-40.

39. Decker DA, Pettinga JE, VanderVelde N, Huang RR, Kestin L, Burdakin JH. Estrogen replacement therapy in breast cancer survivors: a matched-controlled series. Menopause. 2003;10:277-85.

40. DiSaia PJ, Brewster WR, Ziogas A, Anton-Culver H. Breast cancer survival and hormone replacement therapy: a cohort analysis. Am J Clin Oncol. 2000;23:541-5.

41. O'Meara ES, Rossing MA, Daling JR, Elmore JG, Barlow WE, Weiss NS. Hormone replacement therapy after a diagnosis of breast cancer in relation to recurrence and mortality. J Natl Cancer Inst. 2001;93:754-62.

42. Beckmann MW, Jap D, Djahansouzi S, Nestle-Krämling C, Kuschel B, Dall P, et al. Hormone replacement therapy after treatment of breast cancer: effects on postmenopausal symptoms, bone mineral density and recurrence rates. Oncology. 2001;60:199-206.

43. Committee on Practice Bulletins-Gynecology. ACOG practice bulletin no. 126: management of gynaecologic issues in women with breast cancer. Obstet Gynecol. 2012;119(3):666-82.

44.• Runowicz CD, Leach CR, Henry NL, Henry KS, Mackey HT, Cowens-Alvarado RL, et al. American Cancer Society/American Society of Clinical Oncology Breast Cancer Survivorship Care guideline. J Clin Oncol. 2016;34(6):611-35. This guideline provides recommendations to assisting primary care and other clinicians in the care of female adult survivors of breast cancer.

45. Santen RJ. Vaginal administration of estradiol: effects of dose, preparation and timing on plasma estradiol levels. Climacteric. 2015;18(2):121-34.

46. Holmberg L, Anderson H. HABITS steering and data monitoring committees. HABITS (hormonal replacement therapy after breast cancer-is it safe?), a randomised comparison: trial stopped. Lancet. 2004;363(9407):453-5.

47. Holmberg L, Iversen OE, Rudenstam CM, Hammar M, Kumpulainen E, Jaskiewicz J, et al. HABITS study group. Increased risk of recurrence after hormone replacement therapy in breast cancer survivors. J Natl Cancer Inst. 2008;100(7):475-82.

48. von Schoultz E, Rutqvist LE. Stockholm breast cancer study group. Menopausal hormone therapy after breast cancer: the Stockholm randomized trial. J Natl Cancer Inst. 2005;97(7):533-5.

49. Kenemans P, Bundred NJ, Foidart JM, Kubista E, von Schoultz B, Sismondi P, et al. LIBERATE study group. Safety and efficacy of tibolone in breast-cancer patients with vasomotor symptoms: a double-blind, randomised, noninferiority trial. Lancet Oncol. 2009;10(2):135-46.

50. Daly MB, Pilarski R, Berry M, Buys SS, Farmer M, Friedman S, et al. NCCN guidelines insights: genetic/familial high-risk assessment: breast and ovarian, version 2.2017. J Natl Compr Cancer Netw. 2017;15:9-20.

51. Domchek SM, Friebel TM, Singer CF, Evans DG, Lynch HT, Isaacs $\mathrm{C}$, et al. Association of risk-reducing surgery in BRCA1 or BRCA2 mutation carriers with cancer risk and mortality. JAMA. 2010;304:967-75. 
52. Finch APM, Lubinski J, Møller P, Singer CF, Karlan B, Senter L, et al. Impact of oophorectomy on cancer incidence and mortality in women with a BRCA1 or BRCA2 mutation. J Clin Oncol. 2014;32: $1547-53$.

53. Rebbeck TR, Lynch HT, Neuhausen SL, Narod SA, van't Veer L, Garber JE, et al. Prophylactic oophorectomy in carriers of BRCA1 or BRCA2 mutations. N Engl J Med. 2002;346:1616-22.

54. Kauff ND, Satagopan JM, Robson ME, Scheuer L, Hensley M, Hudis CA, et al. Risk-reducing salpingo-oophorectomy in women with a BRCA1 or BRCA2 mutation. N Engl JMed. 2002;346: 1609-15. https://doi.org/10.1056/NEJMoa020119.

55. Parker WH, Broder MS, Chang E, Feskanich D, Farquhar C, Liu Z, et al. Ovarian conservation at the time of hysterectomy and longterm health outcomes in the nurses' health study. Obstet Gynecol. 2009;113:1027-37. https://doi.org/10.1097/AOG. 0b013e3181a11c64.

56. Rocca WA, Grossardt BR, de Andrade M, Malkasian GD, Melton LJ. Survival patterns after oophorectomy in premenopausal women: a population-based cohort study. Lancet Oncol. 2006;7:821-8.

57. Rebbeck TR, Friebel T, Wagner T, Lynch HT, Garber JE, Daly MB, et al. PROSE study group, effect of short-term hormone replacement therapy on breast cancer risk reduction after bilateral prophylactic oophorectomy in BRCA1 and BRCA2 mutation carriers: the PROSE study group. J Clin Oncol. 2005;23:7804-10.

58. Eisen A, Lubinski J, Gronwald J, Moller P, Lynch HT, Klijn J, et al. Hereditary breast cancer clinical study group, hormone therapy and the risk of breast cancer in BRCA1 mutation carriers. J Natl Cancer Inst. 2008;100:1361-7.

59. Kotsopoulos J, Huzarski T, Gronwald J, Moller P, Lynch HT, Neuhausen SL, et al. Hormone replacement therapy after menopause and risk of breast cancer in BRCA1 mutation carriers: a case-control study. Breast Cancer Res Treat. 2016;155:365-73.

60.• Kotsopoulos J, Gronwald J, By K, Al E. Hormone replacement therapy after oophorectomy and breast cancer risk among brca 1 mutation carriers. JAMA Oncol. 2018;4(8):1059-1065. https:// doi.org/10.1001/jamaoncol.2018.0211. A prospective study of BRCA1 mutation carriers suggesting no association between hormone replacement therapy (HRT) use after oophorectomy and risk of breast cancer.

61. Daley A, Stokes-Lampard H, Macarthur C. Exercise for vasomotor menopausal symptoms. Cochrane Database Syst Rev. 2014;11: CD006108.

62. Kroenke CH, Caan BJ, Stefanick ML, Anderson G, Brzyski R, Johnson KC, et al. Effects of a dietary intervention and weight change on vasomotor symptoms in the women's health initiative. Menopause. 2012;19(9):980-8.

63. Anderson DJ, Seib C, McCarthy AL, Yates P, Porter-Steele J, McGuire A, et al. Facilitating lifestyle changes to manage menopausal symptoms in women with breast cancer: a randomized controlled pilot trial of the Pink Women's Wellness Program. Menopause. 2015;22(9):937-45.
64. Crum AJ, Leibiwutz KA, Verghese A. Making mindset matter. BMJ. 2017;356:J674.

65. Dodin S, Blanchet C, Marc I, Ernst E, Wu T, Vaillancourt C, et al. Acupuncture for menopausal hot flushes. Cochrane Database Syst Rev. 2013;(7) Art. No.: CD007410.

66. Saensak S, Vutyavanich T, Somboonporn W, Srisurapanont M. Relaxation for perimenopausal and postmenopausal symptoms. Cochrane Database Syst Rev, 2014. 7 Art. No.: CD008582.

67. NICE NG23 Menopause November 2015 https://www.nice.org.uk/ guidance/ng23

68. Mann E, et al. MENOS1 trial. Lancet Oncol. 2012;13(3):309-18.

69. Ayers B, et al. MENOS2 trial. Menopause. 2012;19(7):749-59.

70. Duijts SFA, et al. EVA trial. J Clin Oncol. 2012;30(33):4124-33.

71. Kingsberg SA, Wysocki S, Magnus L, Krychman ML. Vulvar and vaginal atrophy in postmenopausal women: findings from the REVIVE (Real Women's VIews of Treatment Options for Menopausal Vaginal ChangEs) survey. J Sex Med. 2013;10: 1790-9.

72. Panay N. GSM/VVA: advances in understanding and management. In: Birkhaeuser M, Genazzani AR, editors. Pre-menopause, menopause and beyond. Volume 5: frontiers in gynecological endocrinology. Berlin: Springer; 2018. p. 261-8.

73. Le Ray I, Dell'Aniello S, Bonnetain F, Azoulay L, Suissa S. Local estrogen therapy and risk of breast cancer recurrence among hormone-treated patients: a nested case-control study. Breast Cancer Res Treat. 2012;135(2):603-9.

74. Dew JE, Wren BG, Eden JA. A cohort study of topical vaginal estrogen therapy in women previously treated for breast cancer. Climacteric. 2003;6(1):45-52.

75. Shim SH, Lee SJ, Kim SN. Effects of hormone replacement therapy on the rate of recurrence in endometrial cancer survivors: a metaanalysis. Eur J Cancer. 2014;50:1628-37.

76. Prague JK, Roberts RE, Comninos AN, Clarke S, Jayasena CN, Nash Z, et al. Neurokinin 3 receptor antagonism as a novel treatment for menopausal hot flushes: a phase 2, randomised, doubleblind, placebo-controlled trial. Lancet. 2017;389(10081):1809-20.

77. Fraser GL, Depypere H, Timmerman D, Donders G, Sieprath P, Ramael S, Combalbert J, Hoveyda HR. Clinical evaluation of the NK3 receptor antagonist Fezolinetant (a.k.a. ESN364) for the treatment of menopausal hot flashes. Paper presented at: ENDO 2017, the Endocrine Society's Annual Meeting \& Expo; 3 April 2017; Orlando, FL. Abstract OR 16-5.

Publisher's Note Springer Nature remains neutral with regard to jurisdictional claims in published maps and institutional affiliations. 